\title{
Pengembangan Sistem Keamanan untuk E-Commerce
}

\author{
I Gusti Ngurah Indra Saputra, Gusti Made Arya Sasmita, A. A. K. Agung Cahyawan W. \\ Jurusan Teknologi Informasi, Fakultas Teknik, Universitas Udayana \\ Bukit Jimbaran, Bali, Indonesia \\ michael_bryan_97@yahoo.com, aryasasmita@it.unud.ac.id, agung.cahyawan@unud.ac.id
}

\begin{abstract}
Abstrak
E-commerce adalah kegiatan transaksi barang atau jasa secara jarak jauh antara dua buah perusahaan (business to business) atau antara perusahaan dengan pelanggan (business to consumer). E-commerce telah mempermudah transaksi secara jarak jauh, namun ada resiko keamanan ketika melakukan transaksi pada e-commerce. Sistem keamanan e-commerce secara umum menggunakan bantuan protokol keamanan lainnya seperti SSL (Secure Socket Layer) sehingga sangat bergantung dengan protokol keamanan tersebut. Masalah sistem keamanan e-commerce yang ada diatasi dengan pengembangan sistem keamanan yang menggunakan algoritma keamanan langsung di dalam halaman web. Sistem dirancang mengamankan data transaksi menggunakan algoritma RC6, kunci enkripsi RC6 diamankan dengan algoritma RSA, dan data hasil enkripsi RC6 di-encode dengan Base64. Sistem keamanan yang dihasilkan memblokir data transaksi saat pengguna mengklik tombol submit transaksi, kemudian data transaksi dienkripsi menggunakan algoritma yang diterapkan sebelum dikirim ke server sehingga data transaksi sudah aman tanpa bantuan protokol keamanan lainnya misalnya SSL (Secure Socket Layer).
\end{abstract}

Kata kunci: e-commerce, sistem keamanan, RC6, Base64, RSA

\begin{abstract}
E-commerce is a remote goods or services transaction activity between two company (business to business) or between company with customers (business to consumer). Ecommerce was simplifying the transaction process between producers and consumers, but there is a risk of security issue if doing transactions on e-commerce. A common e-commerce security system using another protocol security e.g. SSL (Secure Socket Layer) so these ecommerce security system is very dependent with these security protocol. The e-commerce security problem was fixed by developed security system that using security system directly on the web page. The system is designed to securing transaction data using RC6 encryption, RC6 encryption key is secured by RSA encryption, and encrypted data is encoded by Base64. The resulting security system is blocking transaction data when users clicking submit transaction button, then these transaction data encrypted using applied algorithm before send it into server so transaction data was secured without aid of another security protocol e.g. SSL (Secure Socket Layer).
\end{abstract}

Keyword: e-commerce, security system, RC6, Base64, RSA

\section{Pendahuluan}

Para pelaku bisnis telah memanfaatkan kegiatan transaksi barang atau jasa secara jarak jauh tanpa harus bertatapan muka secara langsung dengan para pelaku bisnis atau para konsumen lainnya. Teknologi yang memungkinkan untuk melakukan kegiatan transaksi barang dan jasa tersebut dikenal dengan istilah E-commerce. E-commerce adalah teknologi Internet yang berfokus pada kegiatan transaksi barang atau jasa secara jarak jauh tanpa harus bertemu secara langsung. Para pelaku bisnis menggunakan teknologi e-commerce karena teknologi $e$ commerce telah meningkatkan reliabilitas pelaku bisnis dalam kegiatan transaksi, tidak hanya karena kemudahannya, tetapi juga karena teknologi e-commerce sudah mulai terjangkau oleh semua pengguna Internet sehingga memungkinkan para pelaku bisnis untuk memperluas jaringan pemasarannya. Sistem e-commerce harus mengikuti aturan dari beberapa 
infrastruktur, yaitu infrastruktur sistem distribusi barang (flow of good), infrastruktur sistem pembayaran (flow of money), dan infrastruktur sistem informasi yang diterapkan (flow of information) untuk menjaga reliabilitas dalam melakukan transaksi barang atau jasa secara jarak jauh [1]. Aturan infrastruktur tersebut mencakup semua kebutuhan dari sistem $e$ commerce, terutama untuk menjaga kepercayaan dari konsumen. Salah satu cara untuk memenuhi kelancaran dari pemenuhan infrastruktur tersebut yaitu dengan cara memperhatikan aspek keamanan (security) yang harus diberikan kepada para pelanggan.

Sistem keamanan e-commerce adalah sistem yang berfungsi untuk menjaga keamanan dan kenyamanan dalam proses transaksi pada e-commerce. Sistem keamanan pada sistem $e-$ commerce umumnya mengamankan sistem e-commerce dengan bantuan dari protokol keamanan eksternal yang harus di-install ke dalam web server sehingga membuat keamanan dari sistem e-commerce tersebut sangat bergantung dari protokol keamanannya. Kekurangan dari sistem keamanan e-commerce yang ada mendasari pengembangan sistem keamanan $e$ commerce pada penelitian ini. Pengembangan sistem keamanan pada e-commerce yang dirancang mengamankan data transaksi langsung melalui script pada halaman web dan tanpa menggunakan protokol keamanan manapun. Sistem keamanan yang dikembangkan menggunakan sistem keamanan berbasis script algoritma yaitu encoding berbasis Base64, algoritma enkripsi $R C 6$ dan algoritma enkripsi $R S A$. Script dari algoritma keamanan tersebut mengamankan proses transaksi dalam e-commerce langsung dari dalam halaman web sehingga data transaksi telah diamankan tanpa menggunakan protokol keamanan manapun.

Penelitian dalam pengembangan sistem keamanan untuk e-commerce menggunakan beberapa state of the art yang menjadi acuan dan perbandingan yaitu penelitian dari Mateus Mas Belalawe yang membahas penelitian tentang studi kasus pada sistem keamanan $e-$ commerce terhadap situs www.buahonline.com [2], Andre M. R. Wajong dan Carolina Rizki Putri yang membahas penelitian tentang keamanan e-commerce [3], dan Samsul Huda dkk. membahas penelitian tentang implementasi keamanan e-commerce yang menggunakan schnorr digital signature [4]. Ketiga penelitian tersebut menggunakan sistem keamanan ecommerce yang mengandalkan protokol keamanan eksternal yaitu SSL (Secure Socket Layer), TLS (Transport Layer Security), dan PGP (Pretty Good Privacy). Protokol keamanan eksternal tersebut membutuhkan proses instalasi pada sistem server-nya sehingga sistem keamanan dari sistem e-commerce yang digunakan sangat bergantung pada protokol keamanan yang terpasang. Sistem keamanan e-commerce yang dikembangkan pada penelitian ini diharapkan mampu mengamankan data transaksi tanpa protokol keamanan yang lainnya seperti SSL.

\section{Metodologi Penelitian}

Metodologi penelitian membahas metode-metode yang dilakukan untuk melakukan penelitian dalam pengembangan sistem keamanan untuk e-commerce. Pengembangan sistem keamanan untuk e-commerce menggunakan beberapa metode dalam penelitian ini yaitu tahap pengerjaan dan penjelasan diagram arsitektur sistem keamanan. Subbab berikut memuat metodologi penelitian yang digunakan untuk melakukan penelitian sistem keamanan yang dilengkapi gambar dan tabel pendukung.

\subsection{Tahap Pengerjaan}

Pengembangan dari sistem keamanan e-commerce menggunakan tahap pengerjaan sebagai berikut:

1. Analisa sistem, yaitu melakukan analisa yang lebih mendalam terhadap sistem transaksi $e$ commerce secara umum.

2. Menentukan pengembangan metode dari sistem keamanan e-commerce.

3. Melakukan perancangan sistem dengan menggunakan perangkat pemodelan sistem untuk menggambarkan setiap proses yang akan ditangani, aliran data, dan proses pengamanan data.

4. Rancangan sistem diaplikasikan ke dalam halaman web baik untuk sisi client maupun sisi server.

5. Pengujian sistem keamanan dan sistem e-commerce secara menyeluruh dari setiap fasilitas atau menu yang ada pada sistem. 


\subsection{Diagram Arsitektur dari Sistem Keamanan}

Sistem keamanan pada e-commerce menggunakan sistem keamanan yang bekerja sepenuhnya menggunakan script pada pemrograman berbasis web yang telah diatur sedemikian rupa dari sisi client dan sisi server. Sistem keamanan pada bagian server menggunakan bahasa pemrograman PHP, sedangan sistem keamanan pada bagian client menggunakan bahasa pemrograman JavaScript. Sistem keamanan e-commerce memiliki arsitektur program yang ditunjukkan oleh Gambar 1.

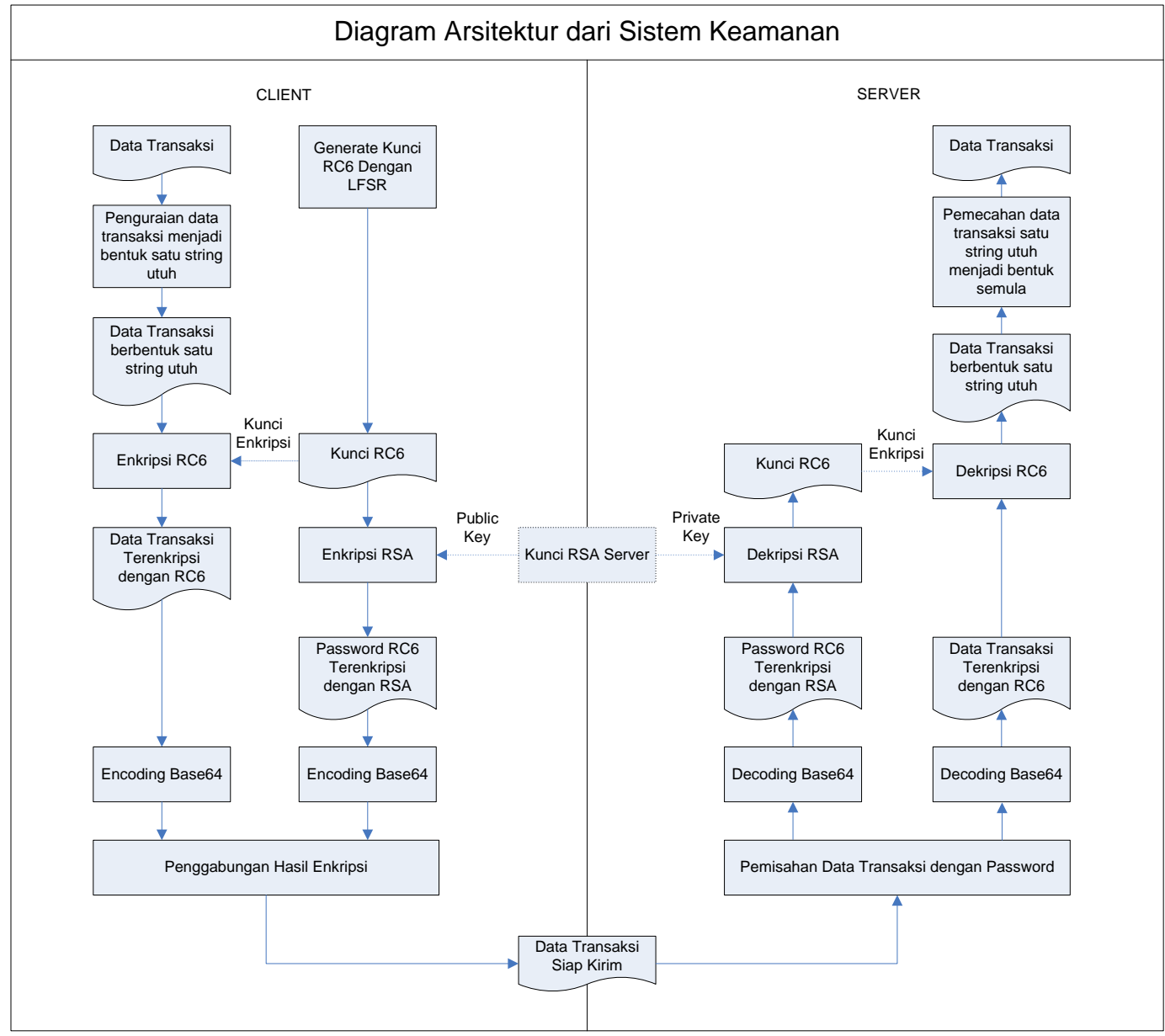

Gambar 1. Diagram arsitektur dari sistem keamanan untuk e-commerce

Gambar 1 menunjukkan cara kerja dari sistem keamanan e-commerce dengan cara dibagi menjadi dua sisi, yaitu pada sisi server dan sisi client. Pengembangan sistem keamanan e-commerce berfokus pada keamanan data transaksi yang dikirimkan dari client karena data transaksi tersebut memuat banyak informasi sensitif yang dikirimkan dari client misalnya data kartu kredit, data username dan password, serta informasi pribadi dari client lainnya misalnya nomor telepon. Cara kerja dari sistem keamanan e-commerce pada sisi client dibahas pada pembahasan berikut:

1. Pelanggan memasukkan data transaksi ke dalam form yang diikuti dengan menekan tombol submit.

2. Sistem keamanan memblokir percobaan transaksi dan memutuskannya setelah mendeteksi percobaan submit.

3. Sistem keamanan meng-generate kunci RC6 secara random dengan algoritma LFSR, kemudian hasil generate diubah menjadi karakter ASCII agar dapat digunakan pada langkah berikutnya.

4. Sistem keamanan mengurai semua input pada data transaksi dengan cara yang digunakan oleh kebanyakan browser, yaitu dengan cara mengambil semua name dan value pada setiap input dalam data transaksi, kemudian merangkainya menjadi satu string dengan 
tanda pemisah "=" (sama dengan). Proses penggabungan string dilakukan pada setiap data input yang telah dimasukkan. Sekumpulan string yang telah digabungkan dari setiap input dirangkai kembali menjadi satu string utuh dengan tanda pemisah "\&" (dan).

5. Sistem keamanan mengenkripsi data transaksi yang telah di-input dengan algoritma $R C 6$ menggunakan kunci $R C 6$ yang di-generate dengan metode $L F S R$ sebelumnya.

6. Kunci $R C 6$ dienkripsi dengan algoritma $R S A$ menggunakan kunci publik dari server.

7. Data transaksi dan kunci $R C 6$ yang telah dienkripsi kemudian di-encode dengan metode Base64 kemudian digabungkan dan dikirimkan ke server.

Cara kerja dari sistem keamanan e-commerce pada sisi server dibahas pada pembahasan berikut

1. Data yang telah sampai di server dipisahan antara data transaksi terenkripsi dengan kunci terenkripsi berdasarkan tanda sama dengan (=).

2. Kunci enkripsi RC6 di-decode dengan metode Base64 kemudian didekripsi dengan algoritma dekripsi $R S A$ menggunakan kunci privat dari server.

3. Data transaksi di-decode dengan metode Base64 kemudian didekripsi dengan algoritma $R C 6$ menggunakan kunci $R C 6$ yang telah didekripsi sebelumnya.

4. Data transaksi diuraikan kembali oleh sistem keamanan ke dalam bentuk variabel input dengan cara memisahkan satu string utuh ke dalam beberapa bagian berdasarkan tanda dan (\&). String yang sudah dipisahkan dimasukkan ke dalam variabel array \$_POST dengan name dan value yang terdapat pada masing-masing string tersebut yang terpisahkan dengan tanda sama dengan (=).

Data transaksi yang telah diolah oleh sistem dekripsi pada server dapat digunakan oleh sistem e-commerce yang mengadopsinya tanpa melakukan penyesuaian pada sistem web secara keseluruhan. Sistem keamanan pada sistem e-commerce dibuat menggunakan pemrograman berbasis web sehingga sistem keamanan dapat mengamankan data transaksi pada sistem e-commerce tanpa menggunakan protokol keamanan lainnya.

\section{Kajian Pustaka}

Kajian pustaka membahas tentang rangkuman dari semua teori yang digunakan di dalam pengembangan sistem keamanan e-commerce. Pengembangan sistem keamanan $e-$ commerce menggunakan beberapa teori yang menunjang kegiatan penelitian yaitu State of the Art, e-commerce, PHP, JavaScript, RC6, Base64, dan RSA. Subbab berikut memuat tentang semua rangkuman teori yang menjadi acuan dalam pengembangan sistem keamanan $e-$ commerce yang dilengkapi dengan gambar dan tabel pendukung.

\subsection{State of the Art}

Penelitian dari sistem keamanan e-commerce menggunakan beberapa state of the art yang menjadi acuan dan perbandingan dalam pembuatan jurnal sistem keamanan e-commerce yang dikembangkan yaitu sebagai berikut:

1. Mateus Mas Belalawe membahas penelitian tentang studi kasus pada sistem keamanan ecommerce terhadap situs www.buahonline.com. Penelitian tersebut membahas sistem keamanan e-commerce yang masih menggunakan protokol keamanan yaitu SSL (Secure Socket Layer), TLS (Transport Layer Services), SET (Secure Electronic Transaction), dan PGP (Pretty Good Privacy) [2].

2. Andre M. R. Wajong dan Carolina Rizki Putri membahas penelitian tentang keamanan ecommerce. Penelitian tersebut membahas sistem keamanan e-commerce yang masih menggunakan protokol keamanan yaitu PKI (Public Key Infrastructure), Digital Signature, Certificate Digital, SSL (Secure Socket Layer), TLS (Transport Layer Services), SET (Secure Electronic Transaction), dan PGP (Pretty Good Privacy) [3].

3. Samsul Huda dkk. membahas penelitian tentang implementasi keamanan E-Commerce yang menggunakan schnorr digital signature. Penelitian tersebut membahas sistem keamanan e-commerce yang masih menggunakan protokol keamanan yaitu SSL (Secure Socket Layer), dan Digital Signature [4].

\subsection{Pengertian e-commerce}

E-commerce adalah kegiatan transaksi barang atau jasa yang dilakukan secara jarak jauh (online) [1]. Proses dalam sistem pembelanjaan e-commerce adalah:

1. Pembuatan web site untuk produk dan layanan 
2. Pemesanan secara online

3. Otomasi akun pelanggan secara aman (melalui nomor rekening atau nomor kartu kredit)

4. Pembayaran secara online

5. Penanganan transaksi pasca pembayaran

\subsection{Sistem keamanan e-commerce}

Sistem keamanan pada e-commerce mencakup beberapa aspek penting yang dijadikan dasar, yaitu aspek-aspek keamanan, macam-macam ancaman, dan solusi dari kekurangan sistem e-commerce. Semua aspek penting pada keamanan e-commerce sangat berpengaruh terhadap tingkat keamanan pada sistem keamanan e-commerce secara keseluruhan. Subbab berikut memuat tentang materi yang berhubungan dengan sistem keamanan e-commerce yang dibahas dalam bentuk subbab.

\subsubsection{Aspek-Aspek Keamanan}

Proses Kriptografi tidak hanya merahasiakan data transaksi tetapi harus memenuhi aspek lainnya yaitu [5]:

1. Authentication, yaitu pengirim pesan harus benar-benar berasal dari pengirim yang bersangkutan.

2. Integrity, yaitu isi pesan harus benar-benar utuh dan tidak diubah oleh orang lain.

3. Nonrepudiation, yaitu pengirim pesan tidak dapat menyangkal bahwa pesan tersebut dikirim oleh yang bersangkutan.

4. Authority, yaitu pesan yang dikirim hanya dapat diubah oleh pihak yang berwenang.

\subsubsection{Macam-macam ancaman}

Macam-macam ancaman yang terjadi dalam sistem e-commerce adalah [6]:

1. System Penetration, yaitu seseorang yang tidak berhak dapat mengakses sistem komputer dan dapat melakukan segalanya.

2. Authorization Violation, yaitu penyalahgunaan wewenang yang dimiliki oleh seseorang yang berhak.

3. Planting, yaitu melakukan penyerangan secara terencana, misalnya memasukkan Trojan Horse dan melakukan penyerangan dengan waktu yang telah ditentukan sebelumnya.

4. Communications Monitoring, yaitu melakukan monitoring semua informasi rahasia.

5. Communications Tampering, yaitu mengubah pesan di tengah jalan oleh penyerang di dalam proses transimisi data dan mengganti sistem server dengan sistem server yang palsu.

6. Denial of Service (DoS), yaitu menolak layanan terhadap client yang berhak.

7. Repudiation, yaitu menolak aktivitas transaksi karena suatu hal yang disengaja atau kesalahan teknis.

\subsubsection{Solusi dari Kekurangan Sistem E-Commerce secara umum}

Solusi dari beberapa masalah yang telah ditemukan untuk meningkatkan keamanan sistem e-commerce yang digunakan saat ini adalah:

1. Menggunakan sistem otentikasi sederhana berbasis hashing yang ditanamkan ke dalam sistem e-commerce untuk melakukan otentikasi pengesahan dari pelanggan.

2. Menggunakan sistem enkripsi simetris $R C 6$ yang diperkuat dengan sistem enkripsi $R S A$ dan sistem encoding dari Base64.

3. Menggunakan sistem enkripsi simetris RC6 hanya untuk mengamankan isi data transaksi sedangkan untuk kunci enkripsi RC6-nya diamankan dengan menggunakan RSA baik dari sisi server maupun dari sisi client.

\section{3. $P H P$}

PHP adalah bahasa pemrograman berbasis web yang dijalankan pada sisi server (server-side). PHP diperkenalkan oleh Rasmus Lerdorf pada tahun 1994 [7]. PHP didirikan untuk Personal Home Page pada awalnya, kemudian sekarang berganti singkatan menjadi PHP: Hypertext Preprocessor.

Kode PHP dapat dibangun pada sistem halaman web dengan cara membangunnya dengan bahasa PHP murni, digabungkan dengan kode HTML, atau dikombinasikan dengan berbagai template engine dan web framework. Kode PHP diproses oleh PHP interpreter yang 
diimplementasikan sebagai bagian modul dari web server. Web server mengirimkan hasil output kepada client dalam bentuk bagian dari halaman web yang dihasilkan karena kode PHP dapat menghasilkan kode HTML web page, gambar, atau data dalam bentuk lainnya.

\subsection{JavaScript}

JavaScript adalah bahasa berbasis web yang dijalankan pada sisi client (client side). JavaScript digunakan dalam pembuatan website agar lebih dinamis dengan cara memerintahkan browser untuk mengeksekusi script JavaScript langsung di dalam halaman HTML [8]. Hasil eksekusi pada JavaScript dapat memanipulasi halaman web serta objek yang ada di dalam halaman web tersebut. JavaScript sangat berbeda dengan Java dan memiliki semantik yang sangat berbeda. Sintaks pada JavaScript diturunkan dari bahasa $C$, namun semantik dan desainnya dipengaruhi oleh bahasa pemrograman self dan bahasa pemrograman scheme.

\subsection{Algoritma $R C 6$}

Algoritma $R C 6$ adalah salah satu dari bentuk standar algoritma Advanced Encryption Standard (AES). Algoritma RC6 ditemukan oleh Ronald L Rivest, M.J.B. Robshaw, R. Sidney dan Y.L. Yin. Algoritma RC6 merupakan pengembangan dari algoritma RC5 [9]. Algoritma RC6 adalah algoritma yang ditulis dalam bentuk parameter $R C 6-w / r / b$, dengan ketentuan sebagai berikut:

1. w merupakan ukuran word dalam satuan bit

2. $r$ merupakan jumlah iterasi selama proses enkripsi

3. b adalah ukuran kunci enkripsi dalam satuan byte.

Algoritma $R C 6$ menggunakan nilai parameter yang telah ditetapkan oleh Standar AES yaitu $\mathrm{w}=32, \mathrm{r}=20$, dan $\mathrm{b}=$ antara 16,24 , dan 32 byte. Cara kerja algoritma $R C 6$ adalah dengan membagi blok yang berukuran 128-bit menjadi empat buah blok yang berukuran 32-bit, kemudian melakukan enam operasi dasar sebagai berikut.

1. A + B: Operasi penjumlahan bilangan

2. $A-B$ : Operasi pengurangan bilangan

3. A xor B: Operasi exclusive-OR (XOR)

4. A $\times$ B: Operasi perkalian bilangan

5. $A \quad<<B$ : A digeser ke kiri sebanyak $B$

6. $A>>>B$ : A digeser ke kanan sebanyak B beriktnya.

Detail dari masing-masing proses pada algoritma $R C 6$ dibahas pada pembahasan

\subsubsection{Pembangkitan Kunci}

Pembangkitan kunci diproses menggunakan nilai parameter untuk algoritma $R C 6-w / r / b$ yaitu $\mathrm{w}=32, \mathrm{r}=20$ dan $\mathrm{b}=32$. Nilai parameter yang telah ditetapkan tersebut adalah nilai standar yang telah ditetapkan oleh standar AES [9]. Algoritma untuk membangkitkan kunci enkripsi pada $R C 6$ dijelaskan pada Gambar 2.

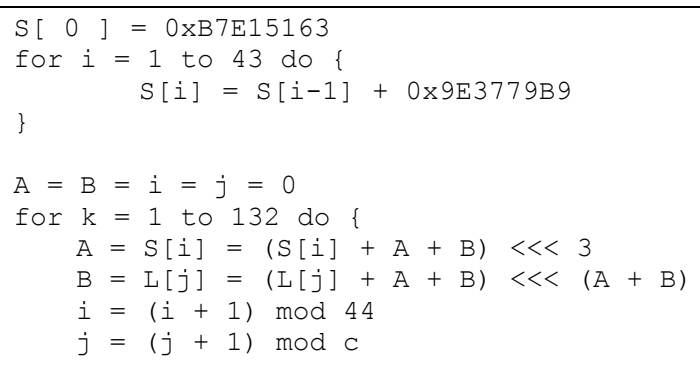

Gambar 2. Pembangkitan kunci pada RC6

Sumber: Muhammad Zulham, 2014

Gambar 2 menunjukkan pseudocode dari algoritma pembangkitan kunci untuk proses enkripsi dan dekripsi pada RC6. Penjelasan detail dari algoritma pembangkitan kunci adalah sebagai berikut: 
1. Pengguna memasukkan sebuah kata kunci (password) sepanjang b byte, password tidak boleh kosong dan tidak boleh melebihi 255 byte.

2. Password yang telah di-input dan di-submit ditempatkan ke dalam array $L$ dengan tipe data 32-bit words. Byte pertama pada password dimasukkan ke dalam array L elemen ke-0, byte kedua pada array L elemen ke-1, dan seterusnya hingga byte terakhir diletakkan pada array L elemen ke b-1.

3. Algoritma RC6 membentuk sub-kunci yang dibentuk berdasarkan array $L$ yang telah dibuat sebelumnya ke dalam array $\mathrm{S}$ yang berukuran 43 tipe data. Array $\mathrm{S}$ elemen ke-0 diberi nilai konstanta 0xB7E15163 dan array S yang berikutnya diberi nilai hasil penambahan dari nilai array S sebelumnya dengan nilai konstanta 0x9E3779B9.

4. Algoritma RC6 melakukan penguatan kunci dengan operasi penggabungan nilai heksadesimal dari nilai array $S$ dengan nilai array $L$ yang diikuti dengan operasi rotasi biner. Proses penguatan kunci dilakukan sebanyak 132 iterasi, dan array $\mathrm{S}$ dari hasil iterasi penguatan kunci selanjutnya digunakan pada proses enkripsi atau dekripsi pada $R C 6$.

\subsubsection{Algoritma Enkripsi $R C 6$}

Proses enkripsi pada algoritma RC6 melibatkan proses pemecahan blok register 128bit menjadi empat buah blok register 32-bit. Proses enkripsi pada algoritma RC6 kemudian dilanjutkan dengan proses whitening awal, iterasi enkripsi sebanyak 20 kali, dan proses whitening akhir [9]. Penjelasan dari algoritma enkripsi RC6 dapat dilihat pada Gambar 3.

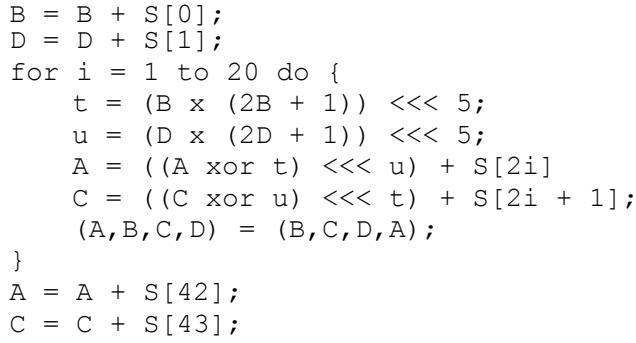

Gambar 3. Algoritma enkripsi pada $R C 6$

Sumber: Scoot Contini, 1998

Gambar 3 menunjukkan pseudocode dari algoritma enkripsi pada RC6. Penjelasan detail dari algoritma enkripsi $R C 6$ adalah sebagai berikut:

1. Algoritma RC6 menggunakan empat buah blok register 32-bit sehingga dapat memproses empat karakter ASCII dalam satu blok dan dapat memproses 16 karakter ASCII dalam satu iterasi. Algoritma RC6 harus mengubah keempat karakter ke dalam bentuk heksadesimal sesuai dengan nomor urut karakter pada tabel ASCIl kemudian mengkonvesinya ke dalam bentuk bilangan heksadesimal.

2. Algoritma RC6 memulai proses whitening awal yaitu menjumlahkan blok $\mathrm{B}$ dengan blok sub kunci $S$ elemen ke-0 dan blok $D$ dengan blok sub kunci $S$ elemen ke-1. Blok sub kunci didapat dari hasil algoritma pembangkitan kunci dari kata kunci yang dimasukkan oleh pengguna.

3. Algoritma RC6 memulai proses iterasi enkripsi sebanyak 20 kali dalam setiap proses enkrpsi yang dilakukan. Setiap iterasi selalu melibatkan dua buah sub-kunci berikutnya, misalnya iterasi 1 menggunakan sub-kunci $S$ elemen ke-2 dan $S$ elemen ke-3, dan seterusnya. Setiap akhir dari masing-masing iterasi, posisi blok yang paling kiri dipindahkan ke posisi paling kanan sehingga urutan blok berubah dari A, B, C, D menjadi B, C, D, A.

4. Algoritma RC6 mengakhiri proses enkripsi dengan proses whitening akhir yaitu menjumlahkan blok $\mathrm{A}$ dengan blok sub kunci $\mathrm{S}$ elemen ke-42 dan blok $\mathrm{C}$ dengan blok sub kunci S elemen ke-43.

\subsubsection{Algoritma Dekripsi RC6}

Proses dekripsi pada algoritma $R C 6$ melibatkan proses pemecahan blok register 128bit menjadi empat buah blok register 32-bit. Proses dekripsi pada algoritma RC6 kemudian dilanjutkan dengan proses whitening awal, iterasi dekripsi sebanyak 20 kali, dan proses 
whitening akhir [9]. Proses dekripsi pada algoritma $R C 6$ merupakan kebalikan dari proses enkripsi pada algoritma RC6. Gambar 4 menjelaskan algoritma dekripsi pada RC6:

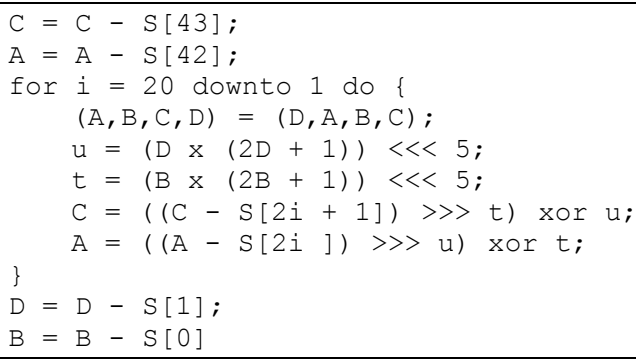

Gambar 4. Algoritma dekripsi pada RC6

Sumber: Scoot Contini, 1998

Gambar 4 menjelaskan tentang pseudocode dari algoritma dekripsi pada $R C 6$. Penjelasan dari algoritma dekripsi $R C 6$ adalah sebagai berikut:

1. Algoritma RC6 hanya bisa menggunakan password dan sub-kunci yang sama dengan proses enkripsi sebelumnya.

2. Algoritma RC6 memulai proses whitening awal yaitu mengurangi blok $\mathrm{C}$ dengan dengan blok sub kunci $S$ elemen ke-43 dan blok $C$ dengan dengan blok sub kunci $S$ elemen ke-42

3. Algoritma RC6 memulai proses iterasi dekripsi sebanyak 20 kali namun urutan iterasinya dilakukan terbalik dari proses enkripsi. Setiap awal dari masing-masing iterasi, posisi blok yang paling kanan dipindahkan ke posisi paling kiri sehingga urutan blok berubah dari $A, B$, C, D menjadi D, A, B, C.

4. Algoritma RC6 mengakhiri proses dekripsi dengan proses whitening akhir yaitu menjumlahkan blok $\mathrm{D}$ dengan blok sub kunci $\mathrm{S}$ elemen ke-1 dan blok $\mathrm{B}$ dengan blok sub kunci $S$ elemen ke- 0 .

\subsection{Algoritma Base64}

Algoritma Base64 adalah algoritma encoding yang mengkonversi karakter ASCII menjadi karakter representasi radix-64 [7]. Algoritma encoding Base64 berfungsi untuk mentransmisikan data ke dalam jaringan secara aman dan terbebas dari kesalahan fungsi transmisi yang disebabkan oleh karakter ASCIl yang memiliki fungsi khusus di dalam operasi tertentu (misalnya karakter dengan kode ASCIl 13 berarti karakter yeng memberi perintah enter).

\subsubsection{Susunan Alfabet Encoding Base64}

Susunan alphabet encoding pada Base64 pada sistem keamanan e-commerce menggunakan sistem alfabet URL and Filename safe, yaitu susunan alfabet Base64 yang sudah dimodifikasi khusus agar dapat digunakan pada web browser tanpa mengalami kendala teknis yang menghambat proses transmisi data (misalnya charater escaping). Susunan alfabet Base64 dapat dilihat pada jurnal publikasi milik Josefsson S. yang berjudul "The Base16, Base32, and Base64 Data Encodings".

\subsubsection{Cara Kerja Algoritma Encoding Base64}

Proses encoding base64 mengambil tiga karakter ASCII dan mengubahnya menjadi empat karakter representasi radix-64 dalam setiap iterasi. Tiga karakter yang diambil oleh algoritma Base64 diubah menjadi bentuk biner, kemudian digabungkan menjadi satu deret bit yang utuh, lalu dipecah kembali menjadi empat deret angka bit yang masing-masing-masing berjumlah sebanyak enam bit. Deret angka biner yang sebanyak enam bit tersebut diubah menjadi karakter representasi radix-64 yang selanjutnya digunakan dalam proses transmisi data [7]. Proses encoding dari algoritma Base64 dapat dilihat pada Gambar 5. 


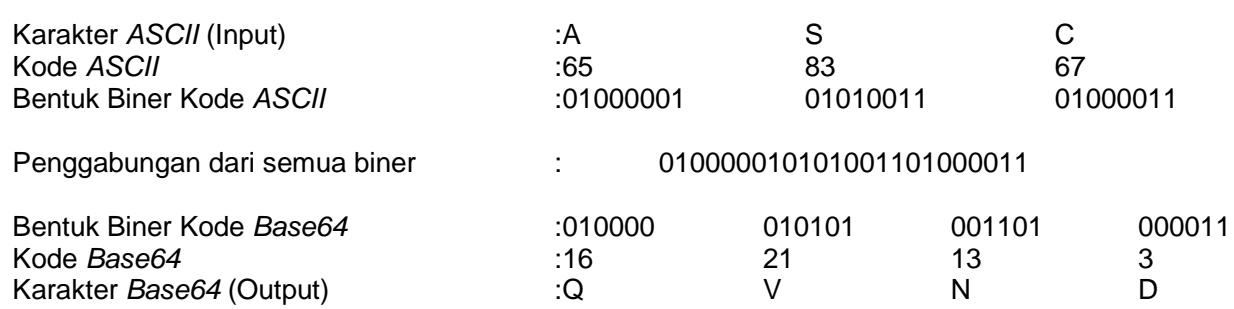

$\begin{array}{lll}: A & S & C \\ : 65 & 83 & 67 \\ : 01000001 & 01010011 & 01000011\end{array}$

: $\quad 010000010101001101000011$

$\begin{array}{llll}: 010000 & 010101 & 001101 & 000011 \\ : 16 & 21 & 13 & 3 \\ : Q & \mathrm{~V} & \mathrm{~N} & \mathrm{D}\end{array}$

\section{Gambar 5. Konversi String ke Base64}

Gambar 5 adalah proses dari konversi string biasa menjadi karakter Base64. Karakter dari string diubah menjadi angka heksadesimal berdasarkan kode ASCII, kemudian dikonversi lagi menjadi angka biner. Semua angka biner hasil konversi dari karakter pada string digabungkan menjadi satu untuk proses selanjutnya. Susunan angka biner dikonversi ke dalam bentuk karakter representasi radix-64 dengan cara diambil setiap enam angka bit, kemudian dikonversi menjadi angka desimal, yang kemudian dikonversi lagi menjadi karakter representasi radix-64.

Setiap tiga karakter pada string ASCII (string biasa) selalu menghasilkan empat karakter base64, dan setiap karakter Base64 selalu berjumlah kelipatan empat. Jika jumlah karakter hasil output dari konversi Base64 tidak berjumlah kelipatan empat, maka hasil output selalu ditambahkan dengan padding (Karakter "=" (sama dengan)).

\subsection{Algoritma RSA}

Algoritma $R S A$ adalah algoritma enkripsi asimetris yang pertama ditemukan di dunia. Algoritma RSA ditemukan oleh Ronald R. Rivest, Adi Shamir dan Leonard Adleman Algoritma pada tahun 1977. RSA menggunakan dua buah kunci yaitu kunci publik untuk proses enkripsi dan kunci privat yang digunakan untuk proses dekripsi [10].

\subsubsection{Pembangkitan Kunci}

Kunci untuk algoritma RSA dihasilkan dengan cara sebagai berikut:

1. Tentukan dua bilangan bulat prima untuk $p$ dan $q$. Bilangan prima $p$ dan $q$ harus dipilih secara acak dan panjang bit harus sama.

2. Hitunglah nilai $n=p q$. Nilai $n$ digunakan sebagai modulus untuk operasi kunci publik dan kunci privat. Panjang kunci dinyatakan dalam bit dan disebut dengan key length.

3. Hitunglah $\varphi(n)=\varphi(p) \varphi(q)=(p-1)(q-1)=n-(p+q-1)$, dengan $m$ adalah fungsi euler totient.

4. Pilih sebuah integer e sehingga $1<e<\varphi(n)$ dan $\operatorname{gcd}(e, \varphi(n))=1$.

5. Tentukan d dengan rumus $d=(1+n m) / e$.

Nilai hasil e dan $\mathrm{n}$ digunakan sebagai kunci publik, sedangkan nilai $\mathrm{d}$ dan $\mathrm{n}$ digunakan sebagai kunci privat.

\subsubsection{Enkripsi dan Dekripsi Algoritma RSA}

Prinsip pada proses enkripsi dan dekripsi pada sistem RSA adalah mengkonversi pesan $\mathrm{m}$ menjadi angka integer, kemudian menggunakan rumus $\mathrm{c}=\mathrm{m}^{\mathrm{e}}(\bmod \mathrm{n})$ untuk proses enkripsi beserta rumus $m=c^{d}(\bmod n)$ untuk proses dekripsi, dengan ketentuan $c$ adalah pesan terenkripsi dengan bentuk integer, $\mathrm{m}$ adalah pesan terdekripsi dengan bentuk integer, e adalah nilai kunci publik, $d$ adalah nilai kunci privat, serta $n$ adalah modulus yang digunakan dalam operasi enkripsi dan dekripsi. Contoh dari proses enkripsi dan dekripsi dapat dilihat pada skenario berikut.

1. Pilih dua bilangan prima yang berbeda, misalnya $p=61$ dan $q=53$

2. Hitunglah nilai $\mathrm{n}=\mathrm{pq}$. Jika $\mathrm{p}=61$ dan $\mathrm{q}=53$, maka $\mathrm{n}=61 \times 53=3233$

3. Hitunglah totient $\varphi(n)=(p-1)(q-1)$. Nilai totient $\varphi(n)$ adalah $(61-1)(53-1)=60 \times 52=3120$

4. Pilih angka e dengan $1<\mathrm{e}<3120$ dan coprime dengan 3120. Angka yang relatif prime dengan e adalah angka yang sama-sama memiliki faktor pembagi terbesar adalah 1. Rumus secara matematis adalah $\operatorname{gcd}(\mathrm{e}, \mathrm{m})=1$. Nilai e adalah lete $=17$

5. Cari angka $d$ sehingga $e^{*} d=1 \bmod (\mathrm{m})$ atau $d=(1+n m) / e$. Nilai $d$ adalah $17 \times 2753 \mathrm{mod}$ $3120=1$ 
6. Hasil perhitungan sebelumnya akan menghasilkan kunci publik $e=17$ dan $n=3233$ dan kunci privat $d=2753$ dan $n=3233$

7. Proses enkripsi menggunakan contoh pesan dengan karakter ASCI/ dengan isi pesan $\mathrm{m}$, fungsi enkripsinya adalah $\mathrm{c}(\mathrm{m})=\mathrm{m}^{17}$ mod 3233. Contoh enkripsi untuk pesan dengan karakter $A S C / /$ bernilai 65 adalah $c=65^{17} \bmod 3233=2790$

8. Proses dekripsi dari pesan ciphertext $\mathrm{c}$ adalah $\mathrm{m}(\mathrm{c})=\mathrm{c}^{2753}$. Contoh pesan dengan karakter ciphertext $\mathrm{d}$ adalah $\mathrm{m}=2790^{2753} \bmod 3233=65$

\section{Hasil dan Pembahasan}

Hasil dari pembahasan pengembangan sistem keamanan e-commerce melibatkan tiga proses pengujian yang dilakukan dari proses penelitian yaitu pengujian submit form, pengujian hasil penyadapan, dan pengujian kecepatan sistem. Masing-masing dari proses pengujian dibahas pada pembahasan berikutnya dalam bentuk subbab. Subbab berikut membahas proses dan hasil dari ujicoba pengembangan sistem keamanan pada e-commerce.

\subsection{Pengujian Saat Melakukan Submit Form}

Pengujian dilakukan menggunakan form pada sistem halaman web yang telah diberikan sistem keamanan. Contoh dari pengujian submit form dapat dilihat pada Gambar 6 .

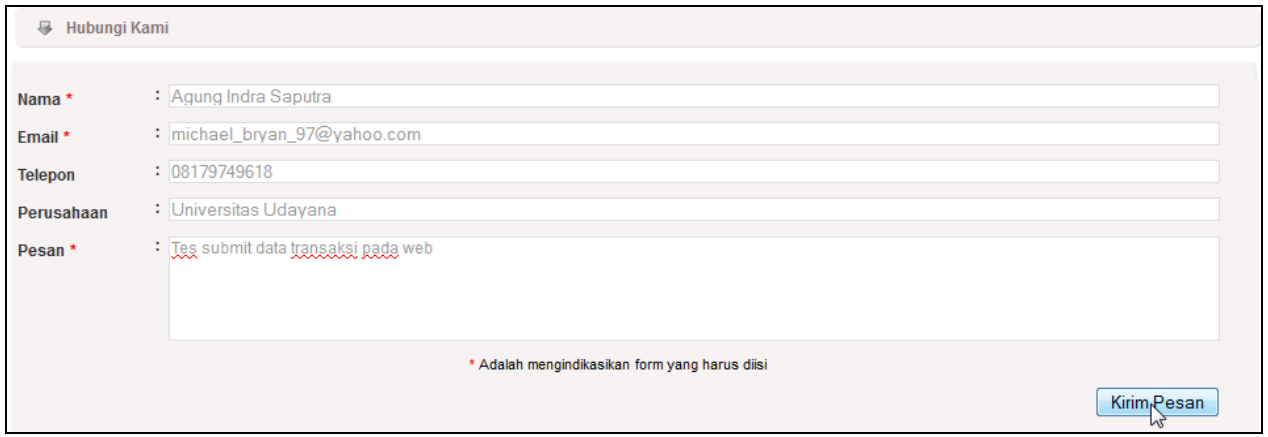

Gambar 6. Form pada halaman web yang diujicobakan

Pengguna memasukkan data transaksi ke dalam form seperti biasa kemudian menekan tombol kirim pesan untuk pengiriman ke server. Sistem keamanan mengamankan data transaksi pengguna ketika pengguna meng-klik tombol kirim pesan dengan cara sebagai berikut:

1. Pencegatan perintah submit secara default

2. Generate kunci $R C 6$ secara random

3. Pengambilan setiap nilai name dan value pada setiap input

4. Escaping dan perangkaian dari nilai name dan value setiap input menjadi satu string utuh

5. Enkripsi rangkaian string dengan algoritma $R C 6$ dengan kunci $R C 6$ yang sebelumnya telah dibangkitkan secara random

6. Encoding hasil enkripsi string dengan algoritma Base64

7. Enkripsi kunci $R C 6$ dengan algoritma $R S A$

8. Encoding hasil enkripsi kunci RC6 dengan algoritma Base64

9. Penggabungan hasil encoding string dengan hasil encoding kunci $R C 6$

10. Pengiriman hasil pengamanan ke server

Data transaksi yang dikirimkan oleh pelanggan dienkripsi dengan algoritma $R C 6$ menggunakan bahasa pemrograman JavaScript, sedangkan data yang telah sampai di server didekripsi dengan algoritma $R C 6$ menggunakan bahasa pemrograman PHP.

\subsection{Hasil Penyadapan}

Data transaksi yang dikirimkan disadap oleh browser Mozilla Firefox menggunakan fitur network pada Mozilla Firefox yang dapat diakses pada menu tools, web developer, network. Proses penyadapan menggunakan fitur dari Mozilla Firefox karena dapat digunakan di dalam web server lokal (localhost). Hasil penyadapan data transaksi tanpa sistem keamanan ecommerce dapat dilihat pada Gambar 7. 


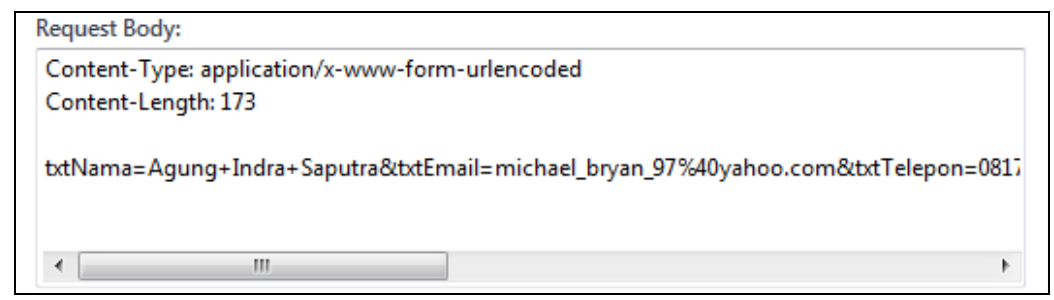

Gambar 7. Hasil penyadapan form tanpa sistem keamanan menggunakan fitur network pada

$$
\text { Mozilla Firefox }
$$

Gambar 7 menunjukkan hasil penyadapan data transaksi tanpa sistem keamanan $e$ commerce. Data transaksi secara umum memiliki informasi pada bagian request body yang berisi nilai name dan value pada masing-masing input yang dikirimkan dengan bentuk plaintext. Hacker dapat melihat isi dari data yang dikirimkan ke dalam server jika sistem e-commerce tidak menggunakan sistem keamanan. Sistem keamanan e-commerce berfungsi untuk mengenkripsi data transaksi yang dikirimkan sehingga hacker tidak dapat melihat isi dari data transaksi setelah disadap. Hasil penyadapan data transaksi dengan sistem keamanan $e-$ commerce dapat dilihat pada Gambar 8.

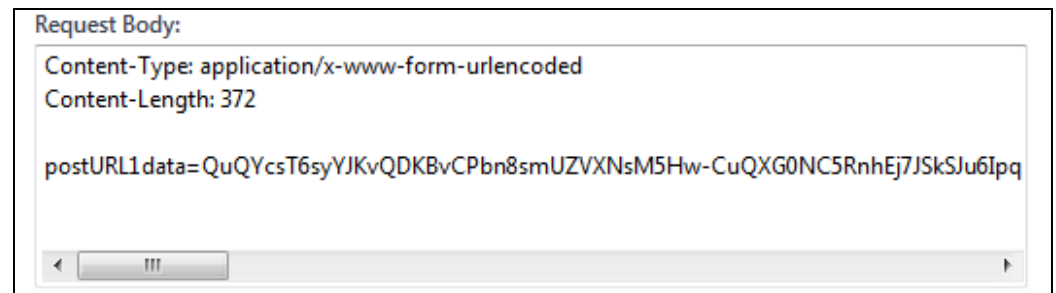

Gambar 8. Hasil penyadapan form dengan sistem keamanan menggunakan fitur network pada Mozilla Firefox

Gambar 8 menunjukkan hasil penyadapan data transaksi dengan sistem keamanan. Sistem keamanan pada e-commerce berfungsi untuk menggabungkan semua nilai name dan value pada semua input di dalam form, kemudian mengenkripsinya dengan algoritma RC6 dan mengirimkannya sebagai value dari input name postURL1data. Sistem keamanan tersebut berfungsi untuk mencegah hacker untuk membaca isi pesan yang dikirimkan ke server sehingga data yang dikirimkan tetap aman.

\subsection{Uji Kecepatan Sistem}

Pengujian kecepatan pada sistem keamanan e-commerce membandingkan kecepatan sistem web sebelum diberikan sistem keamanan dengan sesudah diberikan sistem keamanan. Kecepatan pada sistem web tanpa sistem keamanan dapat dilihat pada Gambar 9.

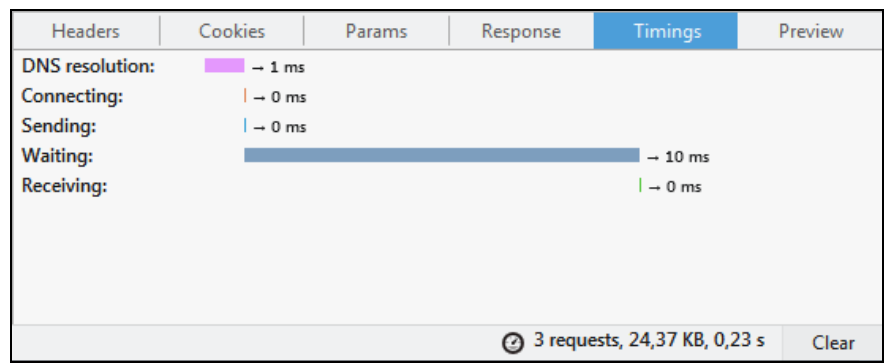

Gambar 9. Hasil pengujian dari sistem web tanpa sistem keamanan

Gambar 9 menunjukkan hasil pengujian kecepatan untuk submit form pada halaman web tanpa sistem keamanan yaitu selama 0,23 detik dengan jumlah request sebanyak 3 requests. Lama waktu yang dibutuhkan untuk proses waiting response dari server adalah $10 \mathrm{~ms}$. Kecepatan pada sistem web dengan sistem keamanan yang dihasilkan dapat dilihat pada Gambar 10. 


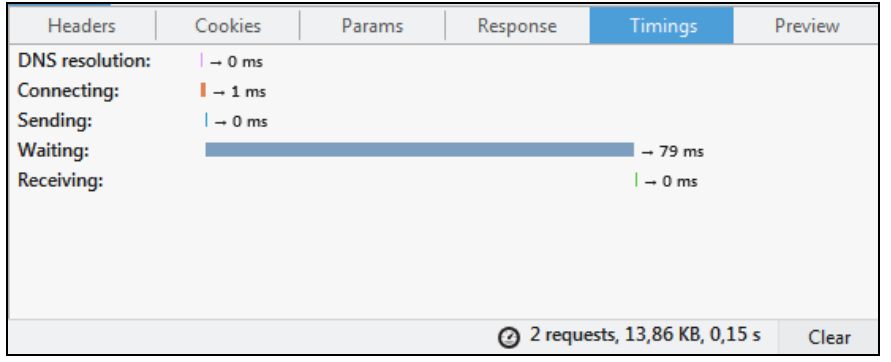

Gambar 10. Hasil pengujian dari sistem web dengan sistem keamanan

Gambar 10 menunjukkan hasil pengujian kecepatan untuk submit form pada halaman web dengan sistem keamanan yang dihasilkan yaitu selama 0,15 detik dengan jumlah request sebanyak 2 requests. Perbedaan waktu antara sistem web tanpa sistem keamanan dan dengan sistem keamanan sebanyak 0,08 detik. Lama waktu yang dibutuhkan untuk proses waiting response dari server adalah $79 \mathrm{~ms}$. Hasil penelitian mencatat perbedaan waktu antara web tanpa sistem keamanan dengan web yang diintegrasikan dengan sistem keamanan adalah 69 ms. Hasil pengujian kecepatan yang diperoleh menunjukkan bahwa terdapat perbedaan yang tidak signifikan dalam masalah kecepatan proses submit form pada sistem web, sehingga sistem keamanan yang dihasilkan dapat diterapkan ke dalam sistem web tanpa mengurangi kecepatan akses pada sistem web.

\section{Kesimpulan}

Sistem keamanan e-commerce yang dihasilkan berfungsi saat pengguna menekan tombol submit setelah pengguna memasukkan data transaksi. Sistem keamanan mengamankan sistem e-commerce dengan cara mengimplementasikan sistem enkripsi simetris $R C 6$, sistem enkripsi asimetris RSA, serta sistem encoding Base64. Data transaksi diamankan menggunakan script dari bahasa pemrograman JavaScript dan PHP sehingga bersifat fleksibel terhadap web server dan dapat mengamankan data transaksi tanpa protokol keamanan lainnya. Sistem keamanan e-commerce dapat diintegrasikan ke dalam sistem e-commerce sehingga tidak terlihat secara kasat mata oleh pengguna sistem e-commerce tetapi dapat mengamankan data transaksi yang dikirimkan sehingga data transaksi tidak dapat disadap oleh pihak luar dan dapat digunakan pada sistem e-commerce tanpa mengurangi kecepatan loading pada web browser.

\section{Daftar Pustaka}

[1]. Himawan, Hidayatullah. Keamanan Transaksi E-Commerce dengan Menggunakan SMS. Yogyakarta: UPN Veteran Yogyakarta. 2008

[2]. Balawe, Mateus Mas. Tinjauan Keamanan Sistem Transaksi dan Pembayaran Pada ECommerce Studi Kasus Toko Online www.buahonline.com. Kupang: STIKOM Artha Buana Kupang. 2013

[3]. Andre M. R. Wajong, Putri, Carolina Rizki. Keamanan dalam Sistem E-Commerce. Jakarta: Bina Nusantara University. 2010

[4]. Huda, Samsul, dkk. Implementasi Sistem Pengamanan E-Commerce Menggunakan Schnorr Digital Signature. Surabaya: Politeknik Elektronika Negeri Surabaya. 2014

[5]. R. A., Esti, Kurniati, A. Pemanfaatan Kriptografi dalam Mewujudkan Keamanan Informasi pada E-Voting di Indonesia. Yogyakarta: UPN Veteran Yogyakarta. 2009

[6]. W. Purbo, Onno, Dkk. Mengenal E-Commerce. Jakarta: Elex Media Komputindo. 2001

[7]. Sholeh, Ahmad Timbul, dkk. Mengamankan Skrip pada Bahasa Pemograman PHP dengan Menggunakan Kriptografi Base64. Garut: Sekolah Tinggi Teknologi Garut. 2013

[8]. B, Indra Yatini. Aplikasi Pengolahan Citra Berbasis Web Menggunakan Javascript dan JQuery. Yogyakarta: STMIK AKAKOM Yogyakarta. 2014

[9]. Defni, Rahmayun, Indra. Enkripsi SMS (Short Message Service) pada Telepon Selular Berbasis Android dengan Metode RC6. Padang: Politeknik Negeri Padang. 2014

[10]. Zulham, Muhammad. Perancangan Aplikasi Keamanan Data Email Menggunakan Algoritma Enkripsi RC6 Berbasis Android. Medan: STMIK Potensi Utama. 2014

[11]. Satriawan, I Wayan Dharma. Aplikasi Enkripsi SMS dengan Metode RSA pada Smartphone Berbasis Android. Denpasar: Universitas Udayana. 2014 